\title{
Correction to: Excessive buccal saliva in patients with Parkinson's disease of the French COPARK cohort
}

\author{
Olivier Rascol ${ }^{1}$. Laurence Negre-Pages ${ }^{2,3} \cdot$ Philippe Damier $^{4} \cdot$ Arnaud Delval $^{5} \cdot$ Pascal Derkinderen $^{4} \cdot$ Alain Destée $^{5}$.

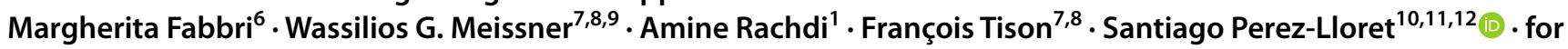 \\ the COPARK Study Group
}

Published online: 21 October 2020

(c) Springer-Verlag GmbH Austria, part of Springer Nature 2020

\section{Correction to: Journal of Neural Transmission https://doi.org/10.1007/s00702-020-02249-0}

The original version of this article unfortunately contained a mistake in Fig. 2 caption. (1) The blank section of the bars represents patients with "drooling"; (2) the section with simple lines represents patients with "no excessive saliva"; and (3) the section with crossed lines represents patients with "sialorrhea".
The correct order would be:

(1) The blank section of the bars represents patients with "no excessive saliva"; (2) the section with simple lines represents patients with "sialorrhea"; and (3) the section with crossed lines represents patients with "drooling".

The correct caption with Fig. 2 is given in the following page.

The original article can be found online at https://doi.org/10.1007/ s00702-020-02249-0.

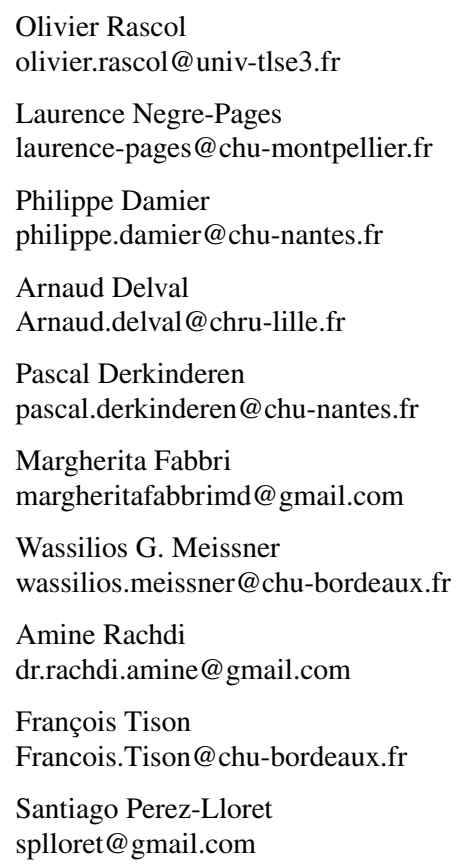

1 Centre D'Investigation Clinique CIC 1436, Services de Pharmacologie Clinique Et Neurosciences, NS-Park/FCRIN Network, NeuroToul COEN Center, Université de Toulouse UPS, CHU de Toulouse, INSERM Toulouse, 37 Allées Jules Guesde, 31000 Toulouse, France
LN Pharma, Toulouse, France

3 Unité de Recherche Clinique Et Epidémiologie, Département D’Information Médicale, Hôpital La Colombière,

Montpellier, France

4 Department of Neurology, NS-Park/FCRIN Network, Université de Nantes, CHU de Nantes, INSERM; CIC 1413, Nantes, France

5 Department of Neurology, U 837, NS-Park/FCRIN Network, Université de Lille, CHU de Lille, INSERM, Lille, France

6 Department of Neuroscience, University of Turin, Torino, Italy

7 Service de Neurologie, NS-Park/FCRIN Network, CHU de Bordeaux, 33000 Bordeaux, France

8 Institut Des Maladies Neurodégénératives, CNRS UMR 5293, Univ. de Bordeaux, 33000 Bordeaux, France

9 Dept. Medicine, University of Otago, Christchurch, and New Zealand Brain Research Institute, Christchurch, New Zealand

10 Biomedical Research Center, Interamerican Open University (CAECIHS-UAI), National Research Council (CONICET), Buenos Aires, Argentina

11 Department of Physiology, School of Medicine, University of Buenos Aires (UBA), Buenos Aires, Argentina

12 Faculty of Medical Sciences, Pontificia Universidad Católica Argentina (UCA), Buenos Aires, Argentina 


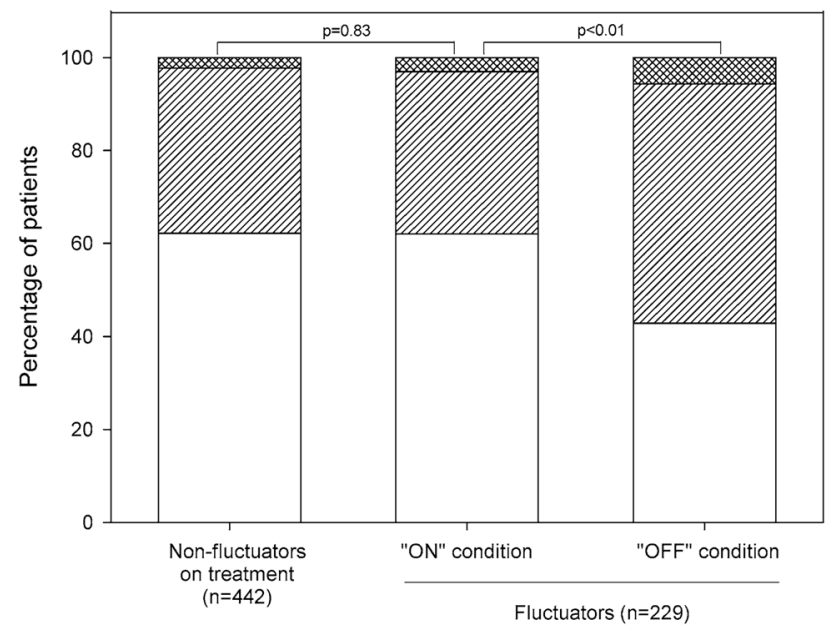

Fig. 2 Proportion of patients with "sialorrhea" ( $\mathscr{K C})$, "drooling" ( $)$, and "no buccal salivation excess" ( $\square$, as evaluated by the UPDRS Item \#6. Differences between non-fluctuators on treatment and fluctuators in the "ON condition" was compared by Chisq test. The comparison between fluctuators in the "ON" and "OFF" conditions was performed by McNemar test
Publisher's Note Springer Nature remains neutral with regard to jurisdictional claims in published maps and institutional affiliations. 